\title{
Flora da Bahia: Lacistemataceae
}

\author{
Lucas Cardoso Marinho ${ }^{1^{*}}$ \& André Márcio Amorim ${ }^{1,2, a}$
}

${ }^{1}$ Programa de Pós-graduação em Botânica, Universidade Estadual de Feira de Santana, Bahia, Brasil.

${ }^{2}$ Departamento de Ciências Biológicas, Universidade Estadual de Santa Cruz, Ilhéus \& Centro de Pesquisas do Cacau, Herbário CEPEC, Itabuna, Bahia, Brasil.

\begin{abstract}
Resumo - É apresentado o levantamento florístico de Lacistemataceae para a Bahia, como contribuição ao conhecimento da flora do estado. Foram reconhecidas três espécies do gênero Lacistema: L. grandifolium, L. lucidum e L. robustum. Lacistema grandifolium tem sua distribuição confirmada no sul da Bahia e L. lucidum é citada pela primeira vez para o Nordeste, a partir de registros na Chapada Diamantina. São apresentados descrições, ilustrações, mapas de distribuição geográfica, e comentários gerais sobre os táxons.

Palavras-chave adicionais: Flacourtiaceae, florística, Lacistema, Malpighiales, taxonomia.
\end{abstract}

\begin{abstract}
Flora of Bahia: Lacistemataceae) - A floristic survey of the Lacistemataceae in Bahia, Brazil, is presented as a contribution to the study of the flora in the state. Three species of the genus Lacistema are recognized: L. grandifolium, L. lucidum and L. robustum. Lacistema grandifolium has its distribution in southern Bahia confirmed and L. lucidum is reported for the first time to Northeast Brazil, based on specimens from the Chapada Diamantina. Descriptions, illustrations, distribution maps and general notes on the taxa are provided.

Additional key words: Flacourtiaceae, floristics, Lacistema, Malpighiales, taxonomy.
\end{abstract}

\section{LACISTEMATACEAE}

Árvores, arvoretas ou arbustos; ramos glabros ou pubescentes. Folhas alterno-dísticas, simples, margens inteiras ou serreadas, peninérveas; pecioladas; estípulas presentes. Inflorescências fasciculadas, axilares, espiciformes ou racemosas; brácteas presentes. Flores unissexuadas ou bissexuadas na mesma inflorescência, monoclamídeas, raro aclamídeas; sépalas ausentes ou 4-6, desiguais, livres ou unidas na base, prefloração imbricada; pétalas ausentes; estame 1, antera biteca, deiscência rimosa; nectário hipógino, discoide, sulcado ou lobado; ovário súpero, 2- ou 3-carpelar, 1-locular, placentação parietal, lóculos 1- ou 2-ovulados, estilete curto ou alongado, estigma tripartido. Fruto cápsula, 3-valvar; sementes 1 ou 2, ariladas ou não.

Lacistemataceae foi tratada como tribo de Flacourtiaceae (Violales sensu Cronquist 1988; veja também Alford 2003), mas sua classificação como uma família em Malpighiales (APG I 1998; APG II 2003; APG III 2009) é bem sustentada em estudos com dados moleculares (Xi et al. 2012). Possui cerca de 15 espécies, nos gêneros Lacistema Sw. e Lozania Mutis, ocorrendo desde o sul do México até a Argentina (Sleumer 1980; Stevens 2015). No Brasil, a família é representada por 10 espécies (Marquete \& Medeiros 2015).

\section{Lacistema Sw.}

Árvores, arvoretas ou arbustos; ramos glabros ou pubescentes. Folhas com lâmina membranácea a

\footnotetext{
*Autor para correspondência: lcmarinho1@gmail.com;

a amorim.uesc@gmail.com

Editora responsável: Ana Maria Giulietti

Submetido: 1 ago. 2014; aceito: 1 abr. 2015

Publicação eletrônica: 28 abr. 2015; versão final: 6 maio 2015
}

coriácea, margens inteiras ou serreadas; estípulas geralmente caducas. Inflorescências em espigas, 1 a numerosas, globosas ou alongadas; bráctea basal geralmente envolvendo toda a flor; bractéolas 2. Flores bissexuadas, monoclamídeas; sépalas 4-6; estame inserido no nectário, antera extrorsa ou introrsa, conectivo espessado; nectário cupuliforme ou lobado, carnoso ou membranáceo; estilete curto ou alongado. Cápsulas obovais a triangulares; sementes 1 ou 2, arilo alvo.

Lacistema inclui 11 espécies de ampla distribuição na região neotropical (Sleumer 1980; Torres \& Ramos 2005). No Brasil, ocorrem 10 espécies (Marquete \& Medeiros 2015), com maior diversidade nas florestas úmidas das Regiões Norte, Sudeste e Sul. Marquete \& Medeiros (2015) mencionam três espécies do gênero para a Bahia. Porém, neste trabalho L. pubescens Mart. não foi confirmada com base nos espécimes examinados. Para a Bahia, foram reconhecidas $L$. grandifolium, L. robustum e L. lucidum, sendo esta última espécie uma nova ocorrência para a Região Nordeste.

\section{Chave para espécies}

1. Ramos pubescentes, lâmina foliar densamente indumentada na face abaxial, ovário glabro

1.1. L. grandifolium

1'. Ramos glabros ou com tricomas esparsos, lâmina foliar glabra ou com tricomas esparsos na face abaxial, ovário piloso.

2. Pecíolo com tricomas esparsos, margem da lâmina foliar serreada na porção distal, filete com tricomas, ovário com tricomas esparsos ......

1.2. L. lucidum

2'. Pecíolo glabro, margem da lâmina foliar inteira, filete glabro, ovário densamente piloso na porção superior 1.3. L. robustum 
1.1. Lacistema grandifolium Schnizl. in Martius, Fl. Bras. 4(1): 284; pl. 81, f. 1. 1857.

Figuras $1 \mathrm{e} 2 \mathrm{~A}-\mathrm{H}$.

Árvores ou arvoretas, até $8 \mathrm{~m}$ alt.; ramos e estípula terminal pubescentes, tricomas simples. Folhas com lâmina $(5-) 13-17,7(-21,2) \times 4-7,3(-10,8) \quad \mathrm{cm}$, subcoriácea a coriácea, oval a oblonga, ápice apiculado, raro arredondado, margens inteiras, base arredondada a obtusa, face abaxial densamente indumentada, tricomas simples; pecíolo 9-15 mm compr., densamente indumentados, tricomas simples. Inflorescências 7-10 mm compr.; raque com tricomas simples; bráctea basal 1-1,2 mm larg., suborbicular; bractéolas ca. $0,3 \mathrm{~mm}$ compr., lineares. Flores esverdeadas a creme; sépalas $5,0,4-0,5 \times 0,1-0,2 \mathrm{~mm}$, lanceoladas a lineares; estame $0,3-0,4 \mathrm{~mm}$ compr., filete glabro, antera ca. $0,15 \mathrm{~mm}$ compr., extrorsa; nectário 4-lobado, carnoso; ovário 1,1-1,5 mm compr., oval, glabro, estilete alongado, glabro. Cápsulas 5-7 $\mathrm{mm}$ compr., obovais, verdes passando a arroxeadas quando maduras, glabras; semente 1, ca. $5 \mathrm{~mm}$ compr.

No Brasil, Lacistema grandifolium ocorre nas Regiões Norte (Acre, Amazonas, Pará e Rondônia), Nordeste (Bahia), Centro-Oeste (Mato Grosso e Mato Grosso do Sul) e Sudeste (Minas Gerais) (Marquete \& Medeiros 2015). G8, H8: floresta ombrófila densa submontana e de terras baixas, entre 50 e 150 m s.n.m. Encontrada com flores entre abril e agosto, e com frutos entre agosto e novembro.

Material selecionado - Ilhéus, Acuípe, $15^{\circ} 05^{\prime} \mathrm{S}, 39^{\circ} 03^{\prime} \mathrm{W}, 5$ maio 2000 (fl.), M.M. Silva et al. 381 (HUEFS); Una, REBIO de

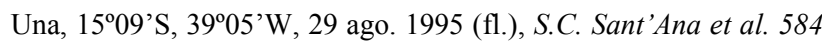
(ALCB, CEPEC, HUEFS, HUESC); Uruçuca, Serra Grande, $14^{\circ} 29^{\prime}$ 'S, $39^{\circ} 06^{\prime}$ W, 21 abr. 2004 (bot.), A.M. Amorim et al. 3971 (CEPEC).

Os materiais de Lacistema grandifolium da Bahia vinham sendo identificados como L. pubescens, que se diferencia pelas folhas com comprimento menor e mais estreitas e pelo ovário com tricomas simples, ocorrendo apenas nos estados do Rio de Janeiro e Minas Gerais na Região Sudeste e, disjuntamente, no Maranhão e Pará na Região Norte (Marquete \& Medeiros 2015).

\subsection{Lacistema lucidum Schnizl. in Martius, Fl. Bras.} 4(1): 282; pl. 79, 81, f. 5. 1857.

Figuras 1 e $2 \mathrm{I}-\mathrm{N}$.

Arvoretas ou arbustos, até $4 \mathrm{~m}$ alt.; ramos com tricomas esparsos próximo à base do pecíolo; estípula terminal com tricomas esparsos na base. Folhas com lâmina 8-19 × 2-7 cm, subcoriácea a cartácea, oblonga a elíptica, ápice apiculado, margens serreadas nos $2 / 3$ da porção distal, base atenuada, face abaxial com tricomas esparsos; pecíolo 5-10 $\mathrm{mm}$ compr., com tricomas esparsos. Inflorescências 4-12 mm compr.; raque com tricomas simples; bráctea basal $0,8-1 \mathrm{~mm}$ larg., suborbicular; bractéolas $0,5-0,6 \mathrm{~mm}$ compr., lineares. Flores esverdeadas a creme; sépalas 5, 0,4$0,5 \times 0,1-0,15 \mathrm{~mm}$, lanceoladas a lineares; estame $0,7-$ $0,8 \mathrm{~mm}$ compr., filete piloso, antera ca. $0,15 \mathrm{~mm}$ compr., extrorsa; nectário 3- ou 4-lobado, carnoso; ovário 6,5-7,5 $\mathrm{mm}$ compr., oval, com tricomas esparsos; estilete alongado, glabro. Cápsulas $8-10 \mathrm{~mm}$ compr., obovais, verdes passando a vermelhas ou arroxeadas quando maduras, com tricomas esparsos; semente 1, ca. $5 \mathrm{~mm}$ compr.

No Brasil, Lacistema lucidum havia sido registrada apenas para os estados do Paraná e São Paulo (Marquete \& Medeiros 2015). Neste trabalho, a espécie é registrada pela primeira vez para a Bahia e para o Nordeste. E6, F6: floresta estacional semidecidual, geralmente em formações ciliares. Floresce entre agosto e abril, com frutificação entre janeiro e abril.

Material selecionado - Ibicoara, fazenda Ponte de Roxo, 12² $49^{\prime}$ S, $41^{\circ} 19^{\prime}$ W, 2 dez. 1986 (fl.), J.D.C. Arouck-Ferreira et al. 409 (CEPEC); Lençóis, rio Lençóis, 12³2'S, 41²3’W, 31 ago. 1993 (fl.), L.S. Funch 678 (HUEFS); Mucugê, Guiné, 1300'S, 41 ${ }^{\circ} 22^{\prime}$ W, 8 fev. 2013 (fl., fr.), A. Rapini \& P.K. Endress 2003

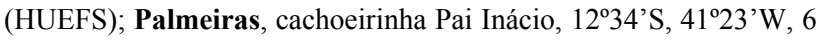
abr. 2004 (fl., fr.), C. van den Berg et al. 1403 (HUEFS).

Lacistema lucidum distingue-se das demais espécies da Bahia por apresentar os ramos e a estípula terminal com tricomas esparsos, margem da lâmina foliar serreada na porção distal, e face abaxial da lâmina (especialmente na nervura central) e pecíolo com tricomas esparsos. A semelhança morfológica entre $L$. lucidum e L. pubescens já havia sido comentada por Torres \& Ramos (2005).

1.3. Lacistema robustum Schnizl. in Martius, Fl. Bras. 4(1): 281; pl. 77. 1857.

Figuras 2O-R, 3 e $4 \mathrm{~A}-\mathrm{D}$.

Árvores, arvoretas ou arbustos, até $10 \mathrm{~m}$ alt.; ramos glabros; estípula terminal glabra. Folhas com lâmina 7,5-21 × 2,8-6,6 cm, coriácea a cartácea, oval a elíptica, ápice agudo a apiculado, margens inteiras, base atenuada, raro obtusa, glabra, raro com tricomas

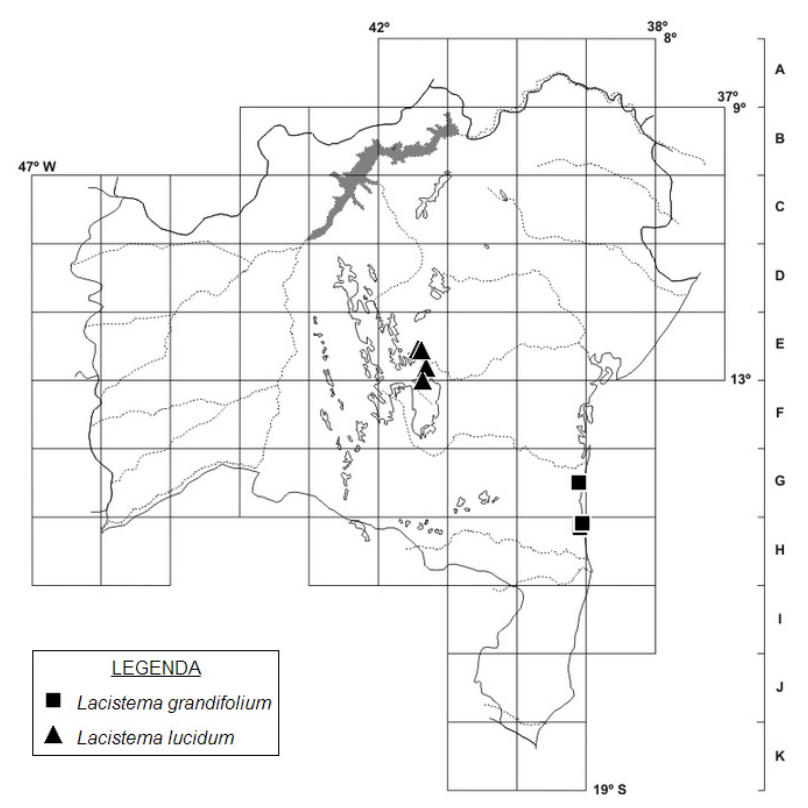

Figura 1. Distribuição geográfica de Lacistema grandifolium e L. lucidum no estado da Bahia. 

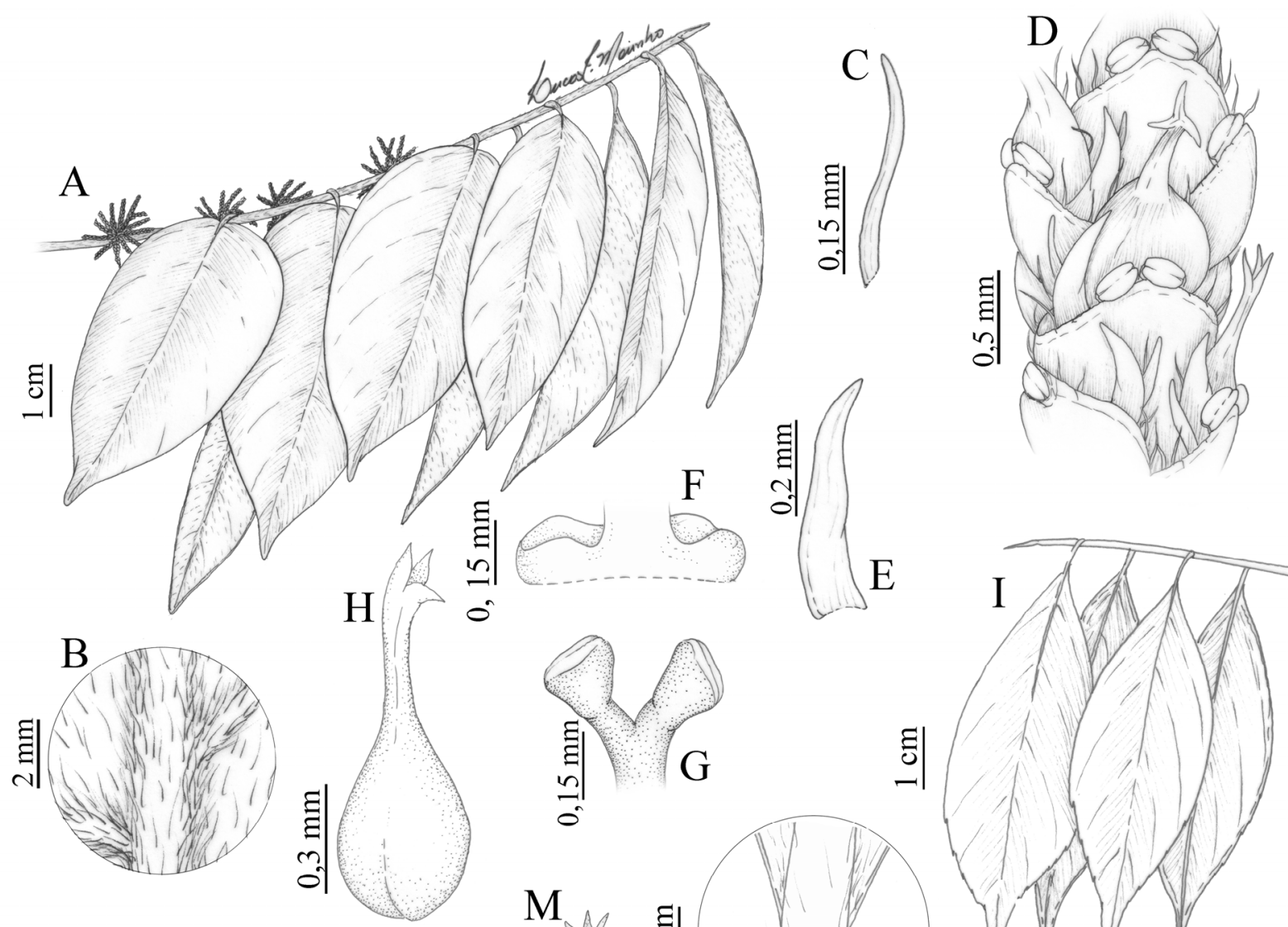

E
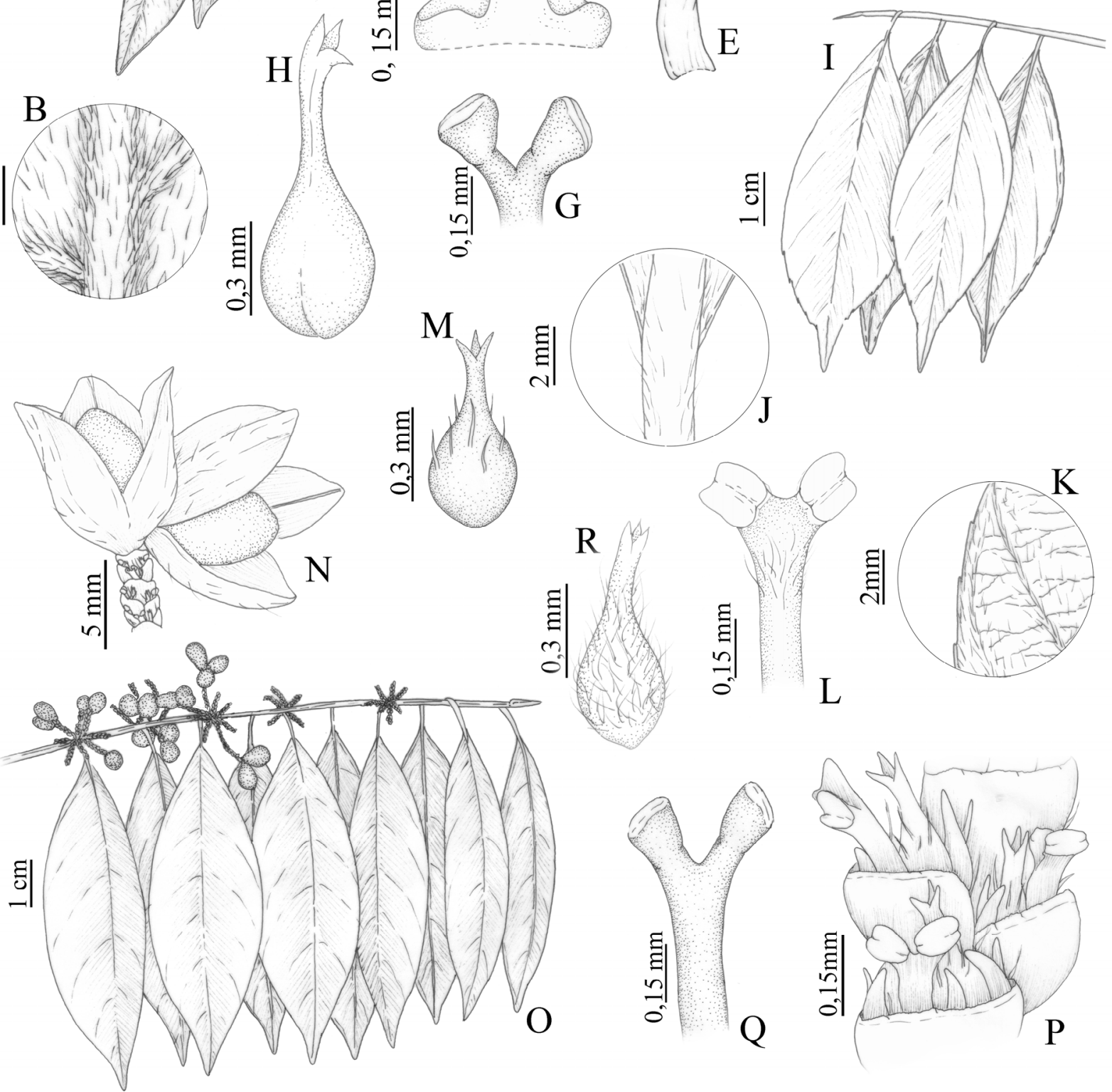

Figura 2. A-H. Lacistema grandifolium: A- ramo com flores; B- detalhe da face abaxial da lâmina foliar evidenciando a nervura central; C- bractéola; D- detalhe da inflorescência; E- sépala; F- nectário; G- estame; H- gineceu. I-N. L. lucidum: I- ramo estéril; J- detalhe do pecíolo com tricomas; K- detalhe da face abaxial da lâmina foliar evidenciando a margem; L- estame com tricomas esparsos no ápice do filete; M- gineceu com tricomas esparsos próximo da inserção do estilete; $\mathbf{N}$ - detalhe da espiga evidenciando as cápsulas. O-R. L. robustum: O- ramo com flores e frutos; P- detalhe da inflorescência; Q- estame com filete glabro; R- gineceu com ovário piloso (A-H- Jardim 1092; I-M- van den Berg 1403; N- Funch 678; O-R- Popovkin 1096). 


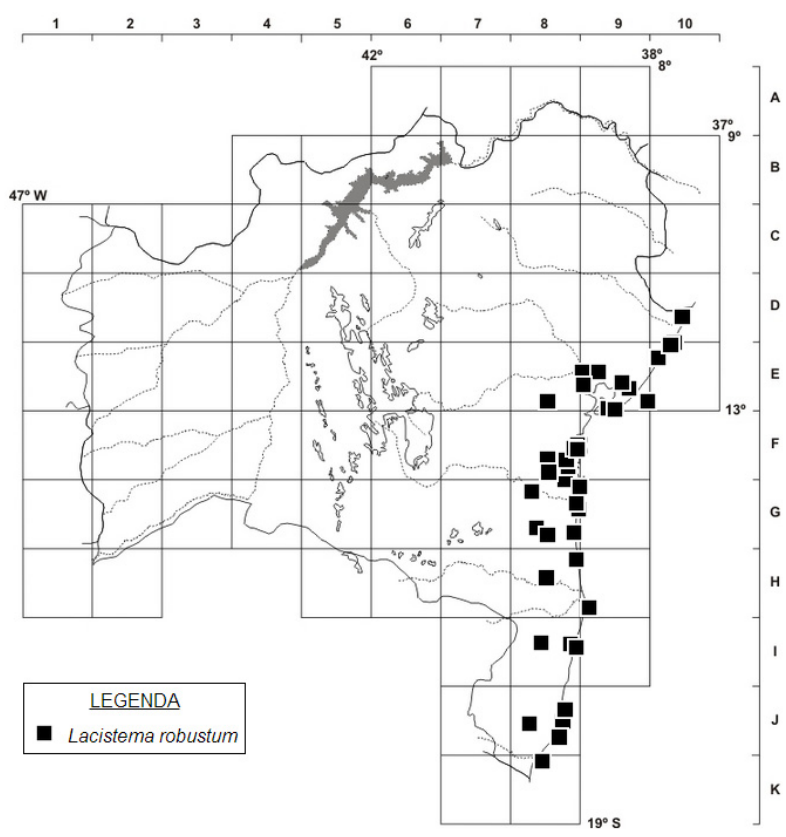

Figura 3. Distribuição geográfica de Lacistema robustum no estado da Bahia.

esparsos na face abaxial; pecíolo $7-13 \mathrm{~mm}$ compr., glabro. Inflorescências 7-15 mm compr.; raque com tricomas simples; bráctea basal 1-1,1 $\mathrm{mm}$ larg., suborbicular; bractéolas ca. 0,4 $\mathrm{mm}$ compr., lineares. Flores esverdeadas a creme; sépalas 5, 0,4-0,5 × 0,1$0,2 \mathrm{~mm}$, lanceoladas a lineares; estame $0,9-1 \mathrm{~mm}$ compr., filete glabro, antera ca. $0,15 \mathrm{~mm}$ compr., extrorsa; nectário 4-lobado, carnoso; ovário $0,7-0,8$ $\mathrm{mm}$ compr., oval, densamente piloso na porção superior; estilete alongado, com poucos tricomas. Cápsulas 7-12 mm compr., obovais, verdes passando a vermelhas ou arroxeadas quando maduras, glabras; semente 1 , ca. $5 \mathrm{~mm}$ compr.

No Brasil, Lacistema robustum é referida para os estados da Bahia, Espírito Santo e Pernambuco (Marquete \& Medeiros 2015). D10, E8, E9, E10, F8, G8, H8, H9, I8, J8, K8: floresta ombrófila densa submontana, montana e de terras baixas, entre 50 e $1.000 \mathrm{~m}$ s.n.m. Floresce durante o ano todo, principalmente entre março e julho, com frutos vistos simultaneamente à floração.

Material selecionado - Alcobaça, rodovia Alcobaça-Teixeira de Freitas, 17³0'S, 39¹5'W, 4 jul. 1979 (fl.), J.L. Hage et al. 282 (CEPEC); Amélia Rodrigues, estrada Feira de Santana-Salvador, 12²6'S, 3844'W, 23 mar. 1994 (fl., fr.), F. França \& E. Melo 959 (CEPEC, HUEFS); Arataca, PARNA Serra das Lontras, $15^{\circ} 10^{\prime} \mathrm{S}$, 39²0’W, 6 ago. 2006 (fl.), M.M. Lopes et al. 998 (CEPEC); Barro Preto, Serra da Pedra Lascada, 14²46'S, 39¹2'W, 3 out. 2006 (fl.), M.M. Lopes et al. 1090 (CEPEC); Belmonte, rodovia BelmonteItapebi, $15^{\circ} 51^{\prime}$ S, $38^{\circ} 52^{\prime} \mathrm{W}, 26$ jul. 1988 (fl.), T.S. Santos et al. 4388 (CEPEC); Cachoeira, RPPN Peninha, 12³7'S, 38 $57^{\circ} \mathrm{W}, 2$ abr. 2006 (fr.), J.S. Santos et al. 193 (ALCB); Cairu, Morro de São Paulo, 13209'S, 3902'W, 4 out. 1996 (bot.), R.M. Harley \& A.M. Giulietti 28419 (HUEFS); Camacan, RPPN Serra Bonita, 15²3'S, 39³3'W, 25 ago. 2007 (fl.), F.M. Ferreira et al. 1320 (CEPEC);
Camaçari, Polo Petroquímico, $12^{\circ} 40^{\prime} \mathrm{S}, 38^{\circ} 18^{\prime} \mathrm{W}, 19$ nov. 2005 (fl.), T.S. Nunes et al. 1340 (HUEFS); Camamu, rodovia Travessão-Camamu, 1400'S, 39³1'W, 15 jun. 1979 (fr.), L.A. Mattos-Silva et al. 508 (CEPEC); Caravelas, Rio do Poço Areinha, 17 $44^{\prime}$ 'S, 39¹8'W, 29 ago. 2011 (fl.), E. Matos et al. 490 (HUEFS); Castro Alves, Serra da Jiboia, 12 ${ }^{\circ} 51^{\prime}$ 'S, 39² $28^{\prime} \mathrm{W}, 7$ maio1993 (bot.), L.P. Queiroz et al. 3147 (CEPEC, HUEFS); Conde, Linha Verde, $12^{\circ} 02^{\prime} \mathrm{S}, 37^{\circ} 42^{\prime} \mathrm{W}, 25$ mar. 1995 (fr.), F. França \& E. Melo 1148 (HUEFS); Entre Rios, 12 ${ }^{\circ} 13$ 'S, 37 $7^{\circ} 53^{\prime} \mathrm{W}, 2$ fev. 2011 (fr.), A.V. Popovkin 834 (HUEFS); Esplanada, Fazenda do Bu, $12^{\circ} 00^{\prime} \mathrm{S}$, 37³9'W, 20 mar. 1996 (fl.), T. Jost \& M.C. Ferreira 249 (ALCB, HUEFS); Eunápolis, 16²2'S, 39³4'W, 14 abr. 1967 (fr.), J.P. Lanna-Sobrinho \& A. Castellanos 1362 (CEPEC); Ibirapitanga,

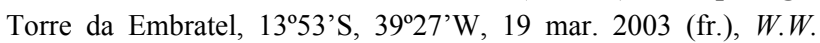
Thomas et al. 13426 (CEPEC); Igrapiúna, Reserva Ecológica Michellin, $13^{\circ} 48^{\prime}$ 'S, $39^{\circ} 10^{\prime} \mathrm{W}, 15$ out. 2008 (fr.), J.L. Paixão \& L. Rocha 1515 (CEPEC); Ilhéus, Banco da Vitória, $14^{\circ} 46^{\prime} \mathrm{S}, 39^{\circ} 05^{\prime} \mathrm{W}$, 28 set. 1994 (fl.), W.W. Thomas et al. 10653 (HUEFS); Itacaré,

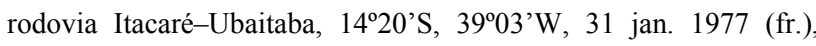
R.M. Harley 18430 (CEPEC); Itagibá, Mata da Antena, 14¹0’S
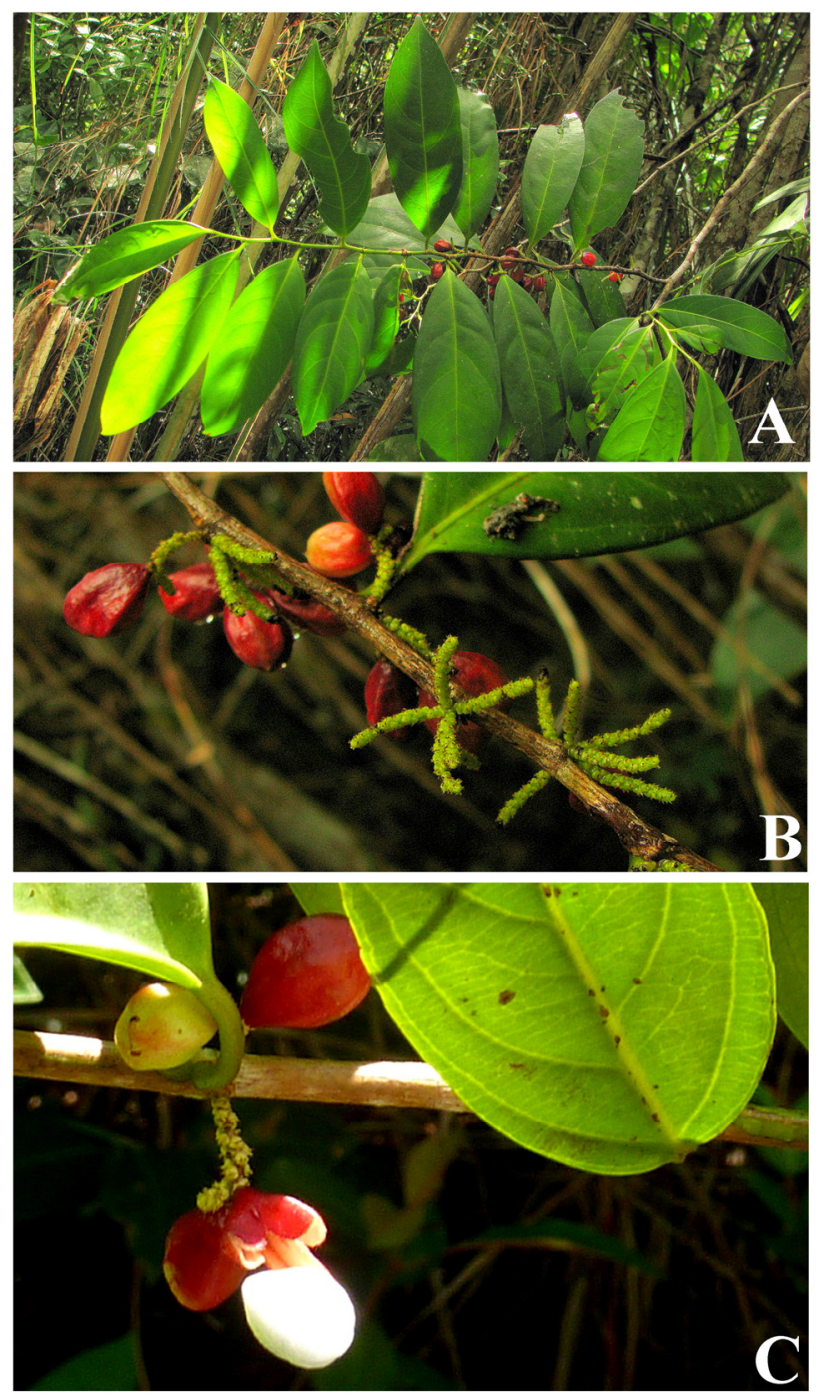

Figura 4. A-C. Lacistema robustum: A- Ramo com folhas em vista adaxial e frutos maduros; B- Detalhe do ramo com inflorescências e frutos maduros; C- Detalhe do fruto maduro evidenciando a semente arilada (Popovkin 1096, fotos: A. Popovkin). 
3942’W, 5 fev. 2009 (fr.), M.L. Guedes et al. 16494 (ALCB); Itanagra, $12^{\circ} 15^{\prime} \mathrm{S}, 38^{\circ} 02^{\prime} \mathrm{W}, 2$ nov. 1980 (bot.), E. Gusmão 487

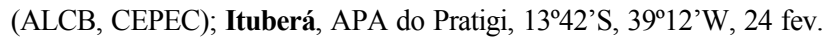
2009 (fr.), F.D. Santana \& L.P. Aguiar 5 (CEPEC); Jandaíra,

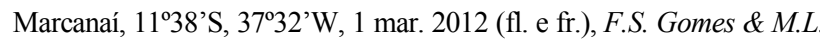
Guedes 1042 (ALCB); Maraú, estrada Ubaitaba-Ponta do Mutá, 1406'S, 3900'W, 3 fev. 1983 (fl.), A.M. Carvalho \& T. Plowman 1429 (CEPEC, HUEFS); Mucuri, 1805'S, 39³3'W, 14 set. 1978 (fl.), S.A. Mori et al. 10525 (CEPEC); Nilo Peçanha, Turrinha, 13³3'S, $39^{\circ} 02^{\prime} \mathrm{W}, 23$ fev. 2000 (fl.), J.G. Jardim et al. 2788 (ALCB, CEPEC, HUEFS, HUESC); Porto Seguro, Parque Nacional Monte Pascoal,

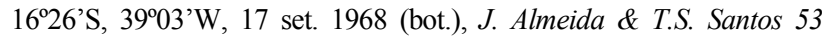

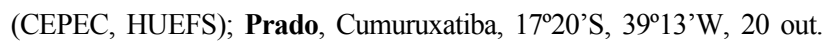
1993 (fr.), W.W. Thomas et al. 10005 (CEPEC); Salvador, Barragem do Cobre, 1258'S, 38³0'W, 2 abr. 2012 (fl., fr.), M.L. Guedes et al. 19796 (ALCB); Santa Cruz Cabrália, 16²3'S, 3908’W, 17 mar. 1966 (fl.), R.S. Pinheiro 9 (CEPEC); Santa Terezinha, Serra da Jiboia, $12^{\circ} 51^{\prime}$ 'S, 39²8'W, 18 mar. 1995 (fl.), F. França et al. 1095 (HUEFS); São Gonçalo dos Campo, fazenda São João, $12^{\circ} 26^{\prime}$ S, $38^{\circ} 58^{\prime} \mathrm{W}, 6$ mar. 1981 (est.), M.L. Guedes \& L. Paganucci 180 (ALCB); São Sebastião do Passé, 12³5'S 38²4'W, 10 jul. 1994 (fl.), M.L. Guedes et al. 3382 (ALCB); Taperoá, 1332'S, 3905’ W, 8 dez. 1986 (bot.), A.M. Carvalho et al. 356 (CEPEC); Teixeira de Freitas, Rancho Alegre,

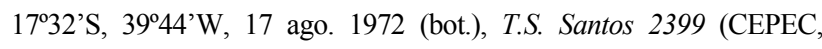
HUEFS); Una, REBIO de Una, $15^{\circ} 09^{\prime} \mathrm{S}, 39^{\circ} 03^{\prime} \mathrm{W}, 11$ out. 2011 (fr.), M. Melito et al. 14 (CEPEC, HUEFS); Uruçuca, Serra Grande-Itacaré, 14²5'S, 3900'W, 1-12 jul. 1991 (est.), W.W. Thomas et al. 6876 (CEPEC); Vera Cruz, 1257'S, 38³6’W, 19 dez. 1992 (fr.), M.L. Guedes et al. 2747 (ALCB, CEPEC, HUEFS); Wenceslau Guimarães, Pico do Urubu, $13^{\circ} 41^{\prime}$ S, 39²8'W, 2 abr. 1993 (fl. e fr.), L.A. MattosSilva \& S.C. Sant'Ana 2930 (CEPEC, HUESC).

Lacistema robustum é amplamente distribuída na Bahia, ocorrendo simpatricamente com L. grandifolium em toda a sua área de ocorrência. Distingue-se de $L$. grandifolium por apresentar as folhas glabras, raro com tricomas esparsos na face abaxial, e estame com o comprimento maior do que o ovário (vs. folhas adultas com tricomas adensados na face abaxial da lâmina e estame com comprimento menor que o ovário).

\section{AGRADECIMENTOS}

Ao CNPq, pela bolsa de Mestrado concedida a LCM, pela bolsa de Produtividade em Pesquisa concedida a
AMA (Processo 306992/2012-4) e pelo financiamento desta pesquisa (Projeto Reflora Malpighiales, Processo 563548/2010-0). Agradecemos também a Alex Popovkin pela concessão das fotografias.

\section{REFERÊNCIAS}

Alford, M.H. 2003. Claves para los géneros de Flacourtiaceae de Perú y del Nuevo Mundo. Arnaldoa 10: 19-38.

APG I. 1998. An ordinal classification for the families flowering plants: APG I. Annals of the Missouri Botanical Garden 85: 531-553.

APG II. 2003. An update of the Angiosperm Phylogeny Group classification for the orders and families of flowering plants: APG II. Botanical Journal of the Linnean Society 141: 399-436.

APG III. 2009. An update of the Angiosperm Phylogeny Group classification for the orders and families of flowering plants: APG III. Botanical Journal of the Linnean Society 161: 105121.

Cronquist, A. 1988. The Evolution and Classification of Flowering Plants. New York Botanical Garden e Allen Press, Inc., New York e Lawrence.

Marquete, R. \& Medeiros, E.S. 2015. Lacistemataceae. In: Lista de Espécies da Flora do Brasil. Jardim Botânico do Rio de Janeiro. Disponível em http://reflora.jbrj.gov.br/jabot/ floradobrasil/FB17847; acesso em 20 feb. 2015.

Sleumer, H.O. 1980. Flacourtiaceae. In: Flora Neotropica Monographs. Vol. 22. The New York Botanical Garden, New York, p. 1-499.

Stevens, P.F. 2015. Angiosperm Phylogeny Website. Versão 12 Jul. 2012 [and more or less continuously updated since]. Disponível em http://www.mobot.org/MOBOT/research/APweb/; acesso em 20 feb. 2015.

Torres, R.B \& Ramos, E. 2005. Lacistemataceae. In: M.G.L. Wanderley, G.J. Shepherd, T. Melhem \& A.M. Giulietti (eds), Flora Fanerogâmica do Estado de São Paulo. Vol. 4. FAPESP \& Rima, São Paulo, p. 231-237.

Xi, Z.; Ruhfel, B.R.; Schaefer, H.; Amorim, A.M.; Sugumaran, M.; Wurdack, K.J.; Endress, P.K.; Matthews, M.L.; Stevens, P.F.; Mathews, S. \& Davis, C.C. 2012. Phylogenomics and a posteriori data partitioning resolve the Cretaceous Angiosperm radiation Malpighiales. Proceedings of the National Academy of Sciences of the United States of America 109: 17519-17524.

\section{LISTA DE EXSICATAS}

Almeida, J. 44, 53 (1.3); Alves, L.J. 18, 38 (1.3); Amorim, A.M. 766, 1069 (1.1), 1363, 2008 (1.3), 3971 (1.1), 4395 (1.3), 5487,6282 (1.1); Arouck-Ferreira, J.D.C. 409 (1.2); Bautista, H.P. 1700 (1.3); Belém, R.P. 3336 (1.3), 3707 (1.1); Borges, R.A.X. 748 (1.3); Brito, H.S. 137 (1.3); Callejas, R. 1669 (1.3); Carvalho, A.M. 356, 806 (1.3), 978 (1.2), 1253, 1429, 4444 (1.3); Carvalho, G. 3 (1.3); Couto, A.P.L. 15, 174, 186 (1.2); Duarte, A.P. 6156 (1.3); Ferreira, F.M. 1320 (1.3); Ferreira, M.C. 868 (1.3); Fiaschi, P. 1372, 2544, 2699 (1.3); França, F. 959, 1095, 1148 (1.3); Freire, L. 31 (1.3); Funch, L.S. 678, 724, 743 (1.2); Gomes, F.S. 794, 1042 (1.3); Guedes, M.L. 180, 265 (1.3), 1510 (1.2), 2747, 3382, 3511, 3673, 4209, 6708 (1.3), 10156 (1.1), 10818, 11948, 16494, 18088, 19386, 19796, 19833 (1.3); Gusmão, E. 487, s/n ALCB 496, ALCB 10024 (1.3); Hage, J.L. 282 (1.3), 801, 821 (1.1); Harley, R.M. 18202 (1.1), 18430, 22062, 22086, 28419 (1.3); Jardim, J.G. 1092 (1.1), 2788, 5335 (1.3); Jesus, N.G. 265 (1.3); Jost, T. 249 (1.3); Lanna-Sobrinho J.P. 1362 (1.3); Loizeau, P.A. 554 (1.3); Lopes, M.M. 998, 1090 (1.3); Martini, A. 47, 62 (1.1); Matos, E. 490, 2739 (1.3); Mattos-Silva, L.A. 508, 981, 1905, 1981, 2171, 2930, 4678, 4979, 4991 (1.3); Melito, M. 14 (1.3); Melo, E. 1364 (1.2); Mori, S.A. 10121, 10308, 10525, 10959, 10967, 
11049, 11760, 12721, 13859 (1.3); Neves, M.L.C. 172 (1.3); Noblick, L.R. 2451 (1.3); Nunes, T.S. 1340 (1.3); Oliveira, D. 6 (1.3); Orge, M.D.R. 235 (1.3); Paixão, J.L. 1515 (1.3); Pinheiro, R.S. 9 (1.3), 1400 (1.1); 1610 (1.3); Popovkin, A.V. 557, 834, 1096 (1.3); Prates, A.R. 205, 289 (1.3); Queiroz, E.P. 2694, 5307 (1.3); Queiroz, L.P. 1444, 2995, 3147 (1.3); Rapini, A. 2003 (1.2); Rocha, E.A. 699 (1.3); Rosas, E. 62 (1.3); Sambuichi, R. 508, 509 (1.3); Santana, D.L. 583 (1.3); Santana, F.D. 5 (1.3); Santos, J.S. 193 (1.3); Santos, R.B. 9 (1.2); Santos, T.S. 463 (1.3), 507 (1.1), 657, 1922, 2399, 2806, 4388 (1.3); Sant'Ana, S.C. 584 (1.1), 866 (1.3), 894 (1.1); Silva, M.M. 381 (1.1); Sobral, M. 5562 (1.3); Souza, C.S.D. 134 (1.3); Thomas, W.W. 6872, 6876, 7237, 7477, 9001 (1.3), 9448 (1.1), 10005, 10653, 11044, 13426 (1.3); Valadão, R.M. 136, 137, 138, 162, 269, 330, 568, 569, 680, 681 (1.3); van den Berg, C. 1403 (1.2); Vinha, S.G. 54, 97 (1.3). 